\title{
Quaderni
}

QUADERNI Communication, technologies, pouvoir

68 | Hiver 2008-2009

Militantisme médical et fabrique des politiques de santé

\section{Medical Activism and Performance Engineering: the Case of Associative Health Centres}

\section{Philippe Warin}

\section{(2) OpenEdition}

Journals

Electronic version

URL: http://journals.openedition.org/quaderni/251

DOI: $10.4000 /$ quaderni.251

ISSN: 2105-2956

Publisher

Les éditions de la Maison des sciences de l'Homme

\section{Printed version}

Date of publication: 5 January 2009

Number of pages: 37-47

\section{Electronic reference}

Philippe Warin, « Medical Activism and Performance Engineering: the Case of Associative Health Centres », Quaderni [Online], 68 | Hiver 2008-2009, Online since 05 January 2009, connection on 22 April 2019. URL : http://journals.openedition.org/quaderni/251 ; DOI : 10.4000/quaderni.251 


\section{$D$ ossier}

medical activism and performance engineering : the case of associative health centres

Philippe Warin

Research Director (CNRS, PACTE Laboratory, IEP, Grenoble)

Scientific manager of Unit for research on non-take up of social benefits and public services (ODENORE)
Recent developments in the french healthcare system seem to have opened new prospects for associative health centres. The revival of interest in them is motivated by various factors, including the difficulties of covering the entire country with an adequate healthcare offering, and of responding appropriately to the decline in certain types of medical specialities in certain areas. These quantitative problems are compounded by others, relative to public health issues: the difficulty of organizing innovative and more effective forms of healthcare for specific groups such as patients with chronic diseases or with particular social characteristics, and that of organizing the regulation of healthcare by monitoring practices and not only measuring expenditures. These concerns correspond to medical professionals' worries about their own medical practice. The majority, especially in the younger generations, refuses the model of the single private practitioner working alone, and seeks new forms of cooperation between practitioners. The costs of setting up a practice are taken into account but are not the only motivation. In France, as in other countries ${ }^{1}$, practitioners also need to work in partnership with colleagues as medical evaluation increasingly endorses patients' eligibility for certain social rights.

Health centres represent a possible solution to these problems and concerns, along with or in competition with other alternatives, for instance healthcare homes or private surgeries where several doctors work in partnership. Although they are characterized by their diversity ${ }^{2}$ - associative, mutual benefit, or municipal - all of them agree that patients stand to gain from healthcare organized in a collaborative and multi-disciplinary way. The États généraux des organisations 
de santé, opened on 30 November 2007, were announced as a major event for reflection on the type and organization of healthcare that should be promoted or even developed to meet the challenges of a redefined offering. When in his opening address, the Health Minister pointed out the medical exodus from disadvantaged urban areas, he oriented debate towards the conditions of attractive general practice ${ }^{3}$. This afforded the associative health centres with an opportunity to reposition themselves lastingly in the general healthcare offer. The aim of this article is not to highlight one form rather than another, but rather to show why and how, in this context, associative health centres have needed to prove their performance.

In the vast category of health centres, now defined in a national agreement, we have focused our study on the centres belonging to the Association de Gestion des Centres de Santé (AGECSA), situated in Grenoble, France. These centres are distinguished from others by the fact that their offering is clearly oriented towards primary healthcare and especially general practice. The example is therefore not one that can be generalized; however, it is interesting in so far as these health centres are currently a focus of attention by the public authorities at national level. In particular, the Haut Commissariat aux Solidarités Actives (HCSA) and the Institut National de Prévention et d'Education pour la Santé(INPES) are interested in the fact that the centres offer the services of general practitioners in certain neighbourhoods.

This article shows how these associative health centres adopt a scientific mode for justifying their work as they endeavour to guarantee their long-term survival ${ }^{4}$. It explains the conditions favouring the take-up of regular evaluation for management purposes, in a militant professional environment that has been built up through a social approach to health. Three types of condition are particularly important for explaining how the challenge of performance can be met when medical professionals adopt a strategic global perspective on their work. These conditions relate to the militant culture of medical professionals, to the political reasons for evaluation, and to the scientific framing of the approach. The following analysis shows how they facilitate militant professionals' adherence to performance engineering.

\section{Dependence on the past}

The AGECSA centres were born in 1973 of the common will of the mutual benefit movement and medical professionals to offer the inhabitants of disadvantaged neighbourhoods in the city of Grenoble healthcare suited to their needs ${ }^{5}$. From their inception, these centres clearly made two choices: first, a medical choice, related both to the lack of a healthcare offer in these neighbourhoods and to the WHO's finding that residential environment is the most important factor influencing healthcare; and, second, militant choice, related to the conviction that a different type of healthcare was desirable, in which the doctor was a worker among workers and an actor in the local population $^{6}$. Today the five centres, of which three are situated in "sensitive urban zones", receive over 22,000 consultants per year.

The political decision of the municipality at the 
time (the mayor, Hubert Dubedout, was a socialist), to use salaried doctors to cover healthcare needs in disadvantaged neighbourhoods, was a form of "past dependency". This dependence has influenced the AGECSA medical professionals' acceptance today of the need to evaluate the organization's performance. By maintaining the spirit of the twofold medical and militant choice, the staff of the healthcare centres, including new recruits, still identifies itself professionally with the legitimacy of a history filled with change. Although that history has been marked by numerous labour conflicts, it has always consisted of adaptations to ensure its survival. Changes in the ambit of the AGECSA centres' work highlight the evolving nature of this form of organization of the healthcare offer. For instance, a centre for medical imagery and a laboratory for medical tests were previously available for the healthcare centres' use. For various reasons (stiff competition, difficulty of investing in new equipment), these activities were abandoned as the centres narrowed down their focus to primary care. Apart from the contextual factors that necessitated such changes, they highlight the AGECSA's marked determination to adapt to circumstances. In its chaotic but never erratic history, the organization has remained loyal to its founding principles. Its professional culture, forged over thirty years, is based on a fighting spirit to defend its dual medical and militant choice, and on realism to avoid becoming stuck in dead-ends. It plays a cohesive role every time the centres are confronted with a demand affecting their organization and their functioning.

Notwithstanding the changes, AGECSA healthcare centres have always provided an original primary care offer which is centred on general practice and organizes complementary care by other professionals. The medical centres group together salaried general practitioners (GPs), and work in collaboration with nursing centres. This offer of general practice is combined with an offer of specialized medicine adapted to the patients' primary needs, especially paediatrics and psychiatry, but also paramedical specialities (physiotherapy, speech therapy, dietetics, and psychology). Thus, specialized medicine and a paramedical offer accompany primary healthcare, often as part of specific therapeutic treatment but also in the framework of prevention (certain forms of cancer, nutritional disturbances, antenatal care). If there was only general practice, these centres could not legitimately be qualified as providers of primary care.

The necessity to evaluate the centres' general performance appeared when their form seemed to be stable and their relations with their partners settled. This necessity was political. In a constantly uncertain financial context, the AGECSA health centres' public partners, concerned about guaranteeing the longevity of the organization, examined its viability. They found that the organization never broke even. It had to appeal to the City of Grenoble and to the General Council of the Isère département for funds to maintain its activities. Today, and notwithstanding the centres' efforts (as regards both staff and productivity), the AGECSA's financial viability is still not guaranteed. Recent forecasts by the financial services of the City of Grenoble show a steady decline in its accounts until 2009. Since the AGECSA's relations with its partners have settled, there is no suspicion regarding the local and regional 
authorities' intentions. They are not threatening to audit the organization, as this has already been done. The idea is more to foresee future developments and to contribute to the AGECSA's repositioning on the local healthcare scene. The necessity to evaluate the organization's performance is therefore explained as a way of creating the right conditions for the health centres' promotion among financial partners other than the local and regional authorities. The required evaluation is thus presented not as a sanction but as a possible tool for promotion. As such it is accepted, for the medical professionals in the organization are used to meeting challenges, especially when they have to prove the overall relevance of the organization, as is the case here. They know however that in a sense it is a matter of "all or nothing”. Mediocre performance might not only turn away new donors but could also weaken its main support. The AGECSA receives most of its funding from local or regional authorities in the form of recurrent grants, sometimes under specific programmes. It is obliged to convince its funders of its efficiency, that is, to show the benefits of its action in relation to its cost. This demonstration requires it to go further than the measurement of its activity (e.g. counting the number of patients treated); it also has to compare costs (material and immaterial) with effects in terms of benefits for the target population's health and for public budgets, owing mainly to its prevention work.

\section{A process of enrolment of medical profession- als at the centres}

The City of Grenoble signed an agreement with the Agence Nouvelle des Solidarités Actives
$(\mathrm{ANSA})^{7}$ on 12 May 2006, to undertake several projects relative to the municipality's social action. Article 1 of the agreement provides for an evaluation of the current system of AGECSA health centres. The decision to involve the ANSA before the 2007 presidential elections was a political strategy. Some people believed that the president of the association, Martin Hirsch, would be in the new government if the socialists won the elections. The idea was therefore to draw the attention of a personality who was likely to become a government minister, to the local associative system in the medical field. The fact that Mr Hirsch finally joined the right-wing government nevertheless satisfied the political initiators of the operation in the left-wing majority on the municipal council of Grenoble. It was hoped that the devolved state authorities (regional and departmental divisions of health and social affairs) and the social institutions of national health insurance would be encouraged to join the financial partnership, and that the AGECSA would have access to other resources for specific projects ${ }^{8}$.

The delegation for coordination of evaluation at the ANSA opted for an enrolment of medical professionals at the health centres. The ANSA's intervention was presented as something beneficial for the health centres. Apart from the assumed proximity between the social, if not political, leanings of those concerned, the ANSA's objectives seemed necessarily to be protective. The AGENCSA saw the aim of the social experiment promoted by the Agency - i.e. to evaluate original practice and to generalize good practice ( $c f$. Note 7) - as a safe bet. Without being sure of the results of the approach, the medical professionals' 
feeling was that the ANSA could but defend the organization's choice of general and preventive medicine. By acting, at the request of the City of Grenoble, for both health and children's interests (via the sociologist Eric Maurin ${ }^{9}$ ), the ANSA shared the currently growing idea in European debate on forms of social protection, that social welfare and public health are "social investment policies" and not policies of compensation or reparation which represent only costs, without benefits ${ }^{10}$. The AGECSA was therefore reassured as to the general aims of the project and even saw it as a source of hope. By asking the ANSA to intervene, the City of Grenoble announced in a sense the main thrusts of a political project favourable to the health centres, just a few months before the municipal elections of March 2008.

As the demand for evaluation was perceived positively by the medical professionals at the centres, the city council and the ANSA committed themselves to demonstrating the health centres' capacity to enter into a logic of valorization of their performance. They wanted to establish favourable conditions for financially re-engaging the national health insurance funds. The fact that the project was drawn up collectively was conducive to trust. It was clearly mentioned that the aim of the project was to promote this type of healthcare offer. The framework document clearly stressed the need to distinguish the centres' missions from their legal or organizational form. This was the only way in which paths for reflection could be proposed that might enable the model and its mode of funding to evolve. Moreover, the tripartite agreement - City, ANSA, AGECSA - did not start with a supposed goal of the centres as a basis for deducing their efficiency. Those who drew up the contract were careful to note that the health centres were not a type of organization of healthcare intended for a specific population. Even though the territorial dimension of the centres was strong, due to their location, it was not in this spirit that the project had been built. The idea was not to reduce them to a device for underprivileged groups, but rather to envisage the conditions for the evaluation of an organization which had the objective inter alia, of responding to a demand for healthcare from a segment of the population that sometimes showed signs of being in a precarious situation.

Unlike other forms of evaluation, the choice was to construct a method that provided more than just a photograph of the situation at a particular point in time, and that afforded the centres with tools to continuously valorize their performance. The aim was to show how and in what form the organization was able to objectify those of its practices that improved the quality of healthcare and contributed to cost-containment. Even though it was not for the project to provide a new contribution to the debate on the definition of a health centre - updated in the recent report by Dominique Acker ${ }^{11}$, General Councillor responsible for medical institutions - it was expected to indicate the forms under which the structure of health centres could be modelled more broadly. The ANSA contacted the health centres of Grenoble explicitly for this purpose. It acted in a spirit of social experimentation that the Haut Commissariat aux Solidarités Actives inspired during the "Grenelle de l'Insertion" (forum for social and professional insertion) held in the city at the end of 2007. The Agency wanted to show that this healthcare offer was efficient so that it 
could be promoted at national level. This very clear discourse persuaded medical professionals that evaluation could be beneficial to the centres. Even before their performance was measured, their trust in the legitimacy of their organization and their medical and militant choice was reinforced.

\section{Favourable conditions for a process of organi- zational innovation}

The health centres' medical staff's acceptance of the evaluation procedure cannot be reduced simply to this process of interessment and deve lopment of trust. It is also important to link their active involvement in the process of objectification of their activity to a set of structural conditions.

Well before the project was launched, the staff was informed by management and by its representatives on the governing board of the organization, of the local authorities' wish to plan grants on the basis of a general review of the centres' financial resources and activities. The arrival of a new management team four years earlier had been announced as the beginning of a new phase in which the aim would be to improve the organization's productivity so that it could attain financial equilibrium and secure its jobs. In this respect the project to evaluate the centres' performance was not a surprise; it appeared to be a logical and acceptable step in the course of events.

At the same time the staff's former inclination to devote some of their working time to collective projects made it easier to take into account the request for evaluation. The centres were used to designing, implementing and monitoring coordination or prevention that went further than healthcare actions as such. For instance, a medical commission existed within the organization under the chairmanship of a general practitioner ; thematic groups were set up and animated; and for several years a person has been in charge of keeping collaborative work between professionals going. A well-oiled operational framework therefore already existed for performance evaluation. Task forces were set up for each of the three sections of the project: medico-economic evaluation of the centres' activity; evaluation of the quality of care; and characterization of clients. These groups, composed of doctors, paramedics, secretaries and administrative staff from the centre, compared their opinions and approaches to the problems discussed at their meetings. The work, conducted intensively over a six-month period during the year 2007, showed that the staff of the health centres adhered to the proposed approach.

The AGECSA also revived its relations with Grenoble University which, in the past, had enabled it to appear as an observatory of healthcare needs and a locus of experimentation in health-related social practices. The project promoters requested the assistance of a medical professor at the university hospital, to evaluate the quality of healthcare, and that of a researcher at the Institut d'Etudes Politiques, to establish a socio-economic characterization of consultants. Both were known to the health centres' medical staff as they had cooperated with the AGECSA and, as recognized experts, had been members of its governing board. The participation of these two academics confirmed the experimental 
nature of the project.

Since the aim of the work was to achieve the most objective results possible, the evaluation tools proposed were carefully chosen for their quality. Independently of the results concerning the centres (which on the whole proved to be good), the medical professionals saw the evaluation as something beneficial. Their organization was open to methodological experimentation that was sure to valorize it if it was positive. As seen through studies in medical sociology, the production of scientific objectivity is one key to reinforce medical practices ${ }^{12}$. The ANSA clearly announced from the outset that it was prepared to disseminate the evaluation method designed at the AGECSA, as a tool for identifying, testing and promoting good practice ${ }^{13}$. To this end, the academics suggested that the actors involved in the project should not try to cobble together a "home-made evaluation" but rather to use effective tools that allowed for comparison (in the sense of benchmarking) with other healthcare offers. For the medico-economic evaluation they recommended : the data processing used by the national health fund for its targeted studies; the reference frameworks and recommendations used by the Health Ministry for studies on the quality of healthcare; the tools developed by the technical support and training centre of the national health fund's medical examination centres (CETAF) and extended by the observatory of non-take-up of benefits and services (ODENORE) to measure the precariousness of consultants from three related points of view : material difficulties; relational media; and individual capacities to act in the face of adversity. The two academics thus acted as intermediaries, in so far as they helped to equip the AGECSA with an ad hoc method which it identified by means of tools that their knowledge and even their own work would help to validate. The evaluation method produced collectively was based on the fact that consultants were taken into account in a multi-dimensional way, as beneficiaries (a medico-economic evaluation), as patients (an evaluation of the quality of the healthcare), and as users (a twofold evaluation: of the users' health, and of their socio-economic level and their relational and other capacities). It was judged positively because it applied the postulate on which all the actors agreed at the outset: that the cost of a healthcare offer cannot be estimated without relating the quality of the services delivered to the patients' characteristics. The professionals adhered to the approach because it afforded them the opportunity to show that the cost of their activities was justified in relation to the results obtained in terms of quality of care for a segment of the population characterized by precariousness. They were satisfied with the results. The ANSA and the public authorities had a method and data showing that the healthcare centres were both evaluable and compared well to other similar healthcare providers.

\section{Conclusion}

This brief review of the introduction of evaluation at associative health centres shows that a militant approach can be objectified in a management practice and even turned into an asset. Without forecasting sustainable results of the approach implemented at the AGECSA, as an actor and observer of this approach I can affirm that until now it has been perceived by medical professionals above all as a tool to demonstrate 
the legitimacy of the healthcare system that they have been defending for over three decades. Even though these medical professionals were not the ones to take the initiative of evaluating the centres' performance, their medical activism has not been an impediment - on the contrary. The conditions in which this evaluative approach has been implemented are highly particular. In several respects the field was ideal: culture of adaptation; trust in political motives; organization willing to respond to a demand for evaluation; scientifically guaranteed evaluation approach. There is therefore no guarantee that performance evaluation would be accepted as willingly in other healthcare systems. In fact it is likely that more persuasion would be required elsewhere to involve healthcare professionals in an approach that is basically managerial (evaluation and comparison of performance).

The fact that the need for performance measurement was not perceived as a risk or provocation stemmed primarily from the approach initially chosen. Had the evaluation project been announced simply as a cost analysis, it would probably have been much more difficult to implement. Acutely aware of their centres' endemic financial problems, the AGECSA medical professionals might have seen it as a trap. However, by presenting the need to evaluate the costs of this healthcare offer, by taking into account the quality of the services (treatment and prevention) delivered to a disadvantaged segment of the population, there was no problem of adherence. On the contrary, the medical staff at the centres voluntarily participated in the collective project because they believed that the proposed approach was in their own interests.
The co-constructed evaluation did not however mask the organization's inability to manage financially with the income generated by the various medical professionals' activities ; it explained that only nursing acts "brought in money" on a regular basis. But the focus was broader than financial matters. The medico-economic evaluation measured and compared patients' effective consumption, over and above the medical professionals' expenditures. It also analysed the doctors' prescribing habits in relation to the national health fund's recommendations. Concerning the amounts reimbursed per category of medical act, the AGECSA's results revealed no noteworthy differences compared to available national data, whereas for other criteria (generalization of the GP gate-keeping device; penetration rate of generic drugs, etc.) they were better. On the whole the comparison was essentially positive, with the exception of auxiliary medical acts. This difference was expected, for it related to the centres' medical and militant goal of favouring access to healthcare in underprivileged neighbourhoods. The fact that reimbursement of auxiliary medical acts - which underprivileged groups generally do without - was higher in the centres than elsewhere was the sign that their availability afforded a more comprehensive approach to healthcare. It was thus a response to the particular needs of the inhabitants of those areas. This is also shown by the far higher consumption of healthcare by patients eligible for free supplementary healthcare coverage (Couverture maladie universelle - Complémentaire - $C M U-C)$ : three times higher than the national average in AGECSA centres (25\% against $8 \%$ ). The evaluation thus accounts for the particular cost of a general practitioner in these areas. But it also shows the positive effects, 
including financial, of this offering in terms of quality (treatment for diabetes, prevention and treatment of obesity, antenatal care, child vaccinations) in population groups where over $60 \%$ are characterized according to the CETAF indicator as being in a precarious or highly precarious situation, and are identified by ODENORE as weakly socialized. Thus, despite the higher expenditures for certain acts, the quality of this healthcare system is remarkably good in certain respects, including complex treatment, for example for diabetes, or treatment requiring the patients' social or cultural acceptance, such as antenatal care in the case of african or north african couple. One can therefore fairly easily infer a correlation between the multi-disciplinary and collaborative form of organization of care, and the observed performance. On the other hand, the collaborative dimension, in the sense of an institutionalized procedure of collective work, inducing shared competencies, formalization of healthcare, and an information system pertaining to health insurance benefits and medical prescriptions which is adapted to these patients, is still being developed in the AGECSA health centres.

The medical staff was able to accept the political demand for evaluation of the centres' performance because the approach immediately broadened the question of financial profitability to include that of efficiency and the relevance of the proposed offer. The evaluation approach was able to compare the resources committed with the observable outcomes among users of the centres, in terms of the quality of care. It furthermore showed that the AGECSA's objectives were suited to the nature of the health-related issues in disadvantaged neighbourhoods. The legitimacy of the militant and medical choice of the centres' staff was confirmed by the quality of healthcare delivered to underprivileged populations. The evaluation of the centres shows, in particular, that it is possible to give prevention the place that it should have in the healthcare system ${ }^{14}$. In other words, the evaluation system confirmed the validity of the Grenoble healthcare centres' medical and militant choice, without simply being a positive presentation of their performance. In the present case, this bias could not exist. Independently of the local result, the ANSA's objective was to design a scientific performance measurement instrument, which could be generalized to the different types of healthcare centre, in order to promote this form of organization more effectively in the general debate on the healthcare offer. Based on these results, the Agency is currently applying the approach designed in Grenoble in other areas, thus playing its part as a promoter of good practice among policy-makers. 
1. Susan Hussey, Pat Hoddinott, Phil Wilson, Jon Dowell, and Rosaline Barbour, « Sickness certification system in the United Kingdom : qualitative study of views of general practitioners in Scotland », in British Medical Journal, Vol. 328, n 88, 2003, pp. 88-92; Peter Sawney, «Current issue in fitness for work certification", in British Journal of General Practice, $\mathrm{n}^{\circ}$ 52, 2002, p. 217-222 ; Elisabeth Nuchtern, « The physician as expert witness. Aspects of an ambivalent role exemplified by expert testimony for legal health insurance ", in Kinderartzl Prax, Vol. 61, $\mathrm{n}^{\circ}$ 4-5, 1993, pp. 174-180.

2. Dominique Acker, Rapport sur les centres de santé, Ministère de la Santé, de la Jeunesse et des Sports, Direction de l'hospitalisation et des soins, June 2007.

3. http://www.sante-jeunesse-sports.gouv.fr/ actualite-presse/presse-sante/discours/etatsgeneraux-organisation-sante-ouverture-travaux.html 4. The present article draws on the report of the Agence Nouvelle des Solidarités Actives, "Centres de santé de la Ville de Grenoble. Bilan des travaux conduits avec l'ANSA ", February 2008, 156 pages. The author of the present article participated in the work reported on, and in drafting the report, under the supervision of Fabien Tuleu, deputy Director of the ANSA. 5. Monika Steffen, Régulation politique et stratégies professionnelles : médecine libérale et émergence des centres de santé, Political Science $\mathrm{PhD}$, Social Science University of Grenoble, March 1983.

6 . The overlapping of the medical choice and the militant choice is thus put into perspective particularly well in the article by Dr Hubert Isnard, "À l'écoute de la santé dans les quartiers », Prévenir, $\mathrm{n}^{\circ}$ 6, November 1982, pp. 65-69.
7. Because they believed that new approaches were worth trying out before being generalized or excluded, 20 persons from various backgrounds created a small social laboratory in the form of a non-profit association. The Agence Nouvelle des Solidarités Actives was officially set up in January 2006 to implement local poverty abatement and return-toemployment programmes, via experimentation. Its creation was a follow-up to the report " Au possible nous sommes tenus. La nouvelle équation sociale», drawn up in 2005 by Martin Hirsch, President of the non-profit organization «Emmaüs-France ». http:// www.solidarites-actives.com/

8. The AGECSA received new funds, from the Haut Commissariat aux Solidarité Actives and the Institut National de Prévention et d'Éducation pour la Santé, for preventive projects.

9. ANSA, Revue succincte d'activité, $\mathrm{n}^{\circ}$ 3, April 2007, pp. 7-8.

10. Gøsta Epsing-Andersen and Bruno Palier, Trois leçons sur l'État-providence, Paris, Seuil, 2008.

11. Dominique Acker, op.cit.

12. Virginie Tournay, Producing medical objectivity: an experimental,replicativesystem of standardization, Sociologie du Travail, Vol. 49, n 2, April-June 2007, pp. 253-267.

13. The "Grenelle de l'insertion" of 23 and 24 November 2007 was part of the "Rencontres de l'expérimentation social». A particular focus of this national event was evaluation, with a forceful demonstration based on foreign experiments and presentations by the Ecole d'Economie de Paris.

14. Concerning France, the reader is referred to the studies and opinions of researchers of the Institut de Recherche et Documentation en Économie de la Santé (IRDES). For example, the point of view of economist Thierry Debrand in Convergence, the magazine of the Secours Populaire Français, February 2008, p. 20. 
$\mathrm{R} \cdot \mathrm{E} \cdot \mathrm{S} \cdot \mathrm{U} \cdot \mathrm{M} \cdot \mathrm{E}$

Les centres de santé associatifs constituent une forme originale d'organisation des soins dans le paysage sanitaire français. Ils présentent quatre caractéristiques fortes : une médecine salariée, pluridisciplinaire mais centrée sur le premier soin, privilégiant le travail en réseau avec des acteurs sociaux locaux, souvent située dans des quartiers désertés par l'offre libérale de soins. Longtemps confinés à pallier une offre libérale défaillante, les centres de santé associatifs connaissent un regain d'intérêt de la part des pouvoirs publics et des organismes payeurs de l'assurance maladie. Leur positionnement particulier ne demeure pas moins extrêmement fragile sur le plan financier et organisationnel. Restant largement adossés à une conception militante de la santé, les professionnels des centres doivent relever le défi d'une gestion équilibrée, sinon excédentaire. Placés devant un défi politique, puisqu'il s'agit de démontrer leur efficience, c'est-à-dire les bénéfices de leur action par rapport à son coût, les centres de santé associatifs recourent à des méthodes d'évaluation qui sont pour eux souvent nouvelles. Pour se doter de cette ingénierie, ils font parfois appel à une expertise extérieure.

\footnotetext{
Medical activism and performance engineering : the case of associative health centres

Associative health centres are an original way of organizing healthcare in France. They have four main characteristics: they employ salaried medical staff; they are multi-disciplinary but focused on primary care; they favour networking with local social actors; and they are often situated in neighbourhoods deserted by private medical practice. For a long time these centres' work was limited to compensating for the
}

lack of private practitioners, but today government authorities and national health funds are showing a new interest in them. Their particular position nevertheless remains fragile from a financial and organizational point of view. The medical professionals employed by these centres, mostly motivated by a militant approach to healthcare, have to meet the challenge of breaking even or at least not running at a loss. Faced with a political challenge, since they have to prove their efficiency - that is, the positive cost/benefit ratio of their action -, the associative health centres are turning to evaluation methods with which they are often unfamiliar. For this purpose they sometimes make use of the services of outside experts. 
